\title{
La dinámica de las inteligencias sociales en la era global. Una visión de hermenéutica analógica aplicada a dos contextos: México y España
}

\author{
Gustavo Antonio Segura Lazcano*, René Lauro Sánchez Vértiz Ruiz* y Carolina Caicedo Díaz*
}

Recepción: 18 de agosto de 2016

Aceptación: 13 de diciembre de 2016

*Universidad Autónoma del Estado de México, México. Correo electrónico: gustavoseguralazcano3@gmail.com; rlrlsv@yahoo.com.mx; ccaidedod@gmail.com

Se agradecen los comentarios de los árbitros de la revista.

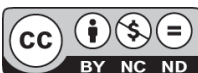

Resumen. A partir de la hermenéutica analógica de Mauricio Beuchot, y con base en la teoría de las inteligencias múltiples de Howard Gardner, se propone la interpretación de la sociedad global destacando los modelos de inteligencia que definen el rumbo de vida de los colectivos. La teoría de las inteligencias sociales ofrece una perspectiva de la globalización que contribuye a esclarecer el sentido de acontecer histórico socio-cultural del mundo actual. Las inteligencias sociales instauran capacidades y poderes simbólicos sobre los entornos e influyen de manera notable en las representaciones y relaciones cotidianas. En condiciones de globalidad algunas inteligencias sociales obtienen posición hegemónica debido a su efectividad y resultados, lo cual induce a individuos y grupos a desplazarse tácticamente hacia las inteligencias: estatista, científica, empresarial y delictiva.

Palabras clave: inteligencias sociales, globalización, hermenéutica analógica.
The Dynamics of Social Intelligences in Globalization. A Vision of Hermeneutics in Two Contexts: Mexico and Spain Abstract. Taking into account both, the analog hermeneutics of Mauricio Beuchot and the theory of multiple intelligences of Howard Gardner, a global society interpretation is proposed, considering the intelligence models that define the course of people's lives. The theory of social intelligence offers a perspective of globalization that reveals the sense of historical and socio-cultural world today.

Social intelligences establish capabilities and symbolic powers over the environment and thereby influence the representations and everyday relationships. Globalization in various social intelligences are hegemonic due to their effectiveness and their results, which causes individuals and groups to move tactically to statist, scientific, business and criminal intelligences.

Keywords: social intelligence, globalization, analog hermeneutics.

\section{Introducción}

El gran dinamismo que muestra la economía mundial y la complejidad que han alcanzado las sociedades postindustriales del siglo xxI, como resultado del avance técnico y el progreso de las telecomunicaciones requeridas por el capitalismo global, emplazan, en el campo de las ciencias sociales, a la irrupción de modelos teóricos y analíticos capaces de interpretar y dar cuenta de las realidades inéditas que enfrenta el mundo actual (Touraine, 2014). Ahora bien, y participando de la búsqueda del paradigma emergente (De Sousa, 2015), este artículo, con base en la hermenéutica analógica sugerida por Mauricio Beuchot (2004), plantea un modelo interpretativo de la sociedad considerando la presencia de múltiples inteligencias sociales coimplicadas en el escenario global.

Nuestra perspectiva presume que junto con la globalización las inteligencias sociales se constituyen en las principales impulsoras de la vida cotidiana. Los individuos y grupos definen acciones y trayectorias que les resultan ventajosas motivados por los referentes simbólicos y la expectativa de trascender las limitaciones impuestas por el sistema capitalista. 
En este texto se denominará inteligencias sociales a los modos de raciocinio que sitúan a los individuos en lógicas diversas a partir de las cuales cada sujeto interpreta y valora su condición particular frente al acontecer social. Se trata de visiones sobre la realidad ${ }^{1}$ que les atañen y desde las que se traman diversas expectativas de acción e interacción social.

El proceso hermenéutico llevado a efecto considera como entidad análoga a la teoría de las inteligencias múltiples formulada por Howard Gardner. Tal visión sostiene en principio que "la inteligencia se organiza a la luz de los orígenes biológicos de cada capacidad para resolver los problemas $[\ldots]$ y cada inteligencia posee una operación nuclear identificable" (Gardner, 2001: 4). Al resultar múltiples las inteligencias que posee cada ser humano, efectivas, pertinentes o no, pueden responder a situaciones concretas de vida. Conservando el sentido original y de manera análoga, ${ }^{2}$ en este trabajo se formula la teoría de las inteligencias sociales orientada a diferenciar los modos colectivos de pensar e intervenir en escenarios impregnados de significaciones globales.

\section{Fundamentación epistémica}

Las transformaciones que ha venido experimentando la humanidad como resultado de la globalización suponen severos cambios en las representaciones y relaciones interpersonales. La vida social al ser intervenida por los embates del mercado mundial y los flujos de información configura un panorama incierto y por demás difuso que demanda ser interpretado con enfoques dinámicos y holísticos. Junto con la noción de realidades inestables surge, en el medio académico, el desafío por superar los modelos teóricos provenientes de la ciencia social del siglo xx que presuponían un raciocinio objetivo, la delimitación clara de los ámbitos de estudio y la existencia de fenómenos recurrentes, aspectos que han venido a ser refutados por los hechos y criterios de validez del conocimiento (De Sousa, 2015).

En la búsqueda de alternativas para comprender el presente desde las ciencias humanas emerge la hermenéutica como una alternativa de reflexión orientada a interpretar las condiciones históricas que lo envuelven. Por medio de la hermenéutica se advierte que toda ciencia es interpretativa de experiencias socio-culturales compartidas y sujetas a lenguajes y tradiciones (Gadamer, 1984).

La voluntad de interpretar induce a revisar los hechos en función de su contexto y contrastar las diversas lecturas que motiva, lo cual confiere a la hermenéutica el carácter de teoría y práctica reflexiva. Existe hermenéutica en todo acto interpretativo que otorga sentido a nuestras significaciones y realizaciones históricas socio-culturales (Velázquez, 2011). Interpretar legitima al pensamiento como palabra y signo que configura las relaciones interpersonales. Interpretar imprime sentido histórico a nuestra existencia al tiempo que obliga a reconocer la valía de otras gramáticas como maneras singulares de construir y estructurar lo real (Gadamer, 2010).

La hermenéutica aproxima a la verdad de lo acontecido; sin embargo, no puede hacerlo de manera plena al estar sujeta inevitablemente a los prejuicios de la cultura (Ferraris, 1998). La hermenéutica analógica de Mauricio Beuchot propone esquivar las interpretaciones extremas, sean éstas equivocas o unívocas, dado que tales versiones trastocan el propósito de comprender y desentrañar el sentido de lo que hacemos. Lo unívoco dogmatiza el pensamiento y lo equívoco extravía la conciencia: ambos impiden el diálogo (Beuchot, 2005).

$\mathrm{El}$ apropiado uso de analogías ofrece una vía alterna de interpretación que evita la declaración conformista y estéril. A través de análogos, tanto hombres comunes como de ciencia han logrado comprender aquello que requerían. Por medio de analogías se estimula la imaginación y fusionan las experiencias que permiten entender fenómenos complejos y descubrir algunas relaciones inéditas. Mediante una interpretación dialéctica que considera lo idéntico y lo diferente, los hechos revelan sentidos ocultos y abren horizontes de significación. Si bien toda analogía resulta condición artificiosa, es necesaria y útil al entendimiento (García, 2001).

Con la finalidad de esclarecer las representaciones colectivas asociadas a la globalización proponemos el uso analógico de la teoría de las inteligencias múltiples de Howard Gardner que analiza el microcosmos cognoscitivo del ser humano. Al desplazar el modelo a una escala global se obtiene la comprensión del macrocosmos social, ámbito donde interactúan y debaten diversas formas de inteligencia. Según la teoría de Howard Gardner, los hombres poseen múltiples inteligencias: lingüística, lógico-matemática, musical, espacial y cinestésico-corporal, intrapersonal e interpersonal (Gardner, 2001). Esta afirmación constituyó un avance significativo para la psicología cognoscitiva ceñida anteriormente a la premisa de la inteligencia única. La teoría de Gardner ha permitido

\footnotetext{
1. La realidad desafía la capacidad humana de hacer legible y asequible las situaciones concretas que enfrentan los colectivos. Asimismo, supone el encuentro de diversos sujetos en un mundo común

2. El empleo de análogos hace que la relación fundamental persista al aproximar dos fenómenos de distinta naturaleza. De igual manera como diversas funciones psíquicas y orgánicas favorecen el desarrollo de una determinada inteligencia, as también individuos y grupos interactúan y contribuyen a que una inteligencia social se traduzca en un modo de vida.
} 
diferenciar diversos procesos neuro-sensoriales, modos de aprendizajes y conductas. ${ }^{3}$

\section{Las inteligencias humanas y su injerencia social}

La palabra inteligencia por su etimología intelligens refiere al entendimiento; sin embargo, considerando su nexo con el vocablo legere se traduce en acción electiva o actividad racional encaminada a una acción certera. Por tanto, el hombre resulta inteligente cuando opta por el mejor curso de acción. Según Howard Gardner al ser múltiples las inteligencias, son diversas las maneras de resolver los problemas de la vida cotidiana. Cada inteligencia implica en su manifestación procesos neuropsicológicos específicos promotores de aprendizajes por medio de los cuales los individuos modifican sus entornos y obtienen resultados favorables. Con antelación a la teoría de las inteligencias múltiples, la noción de inteligencia humana fue considerada una capacidad común, racional, genérica y dominante. 4

Conservando el sentido de mejor elección suscrito a la definición de inteligencia, postulamos que las inteligencias sociales constituyen modelos racionales de interacción grupal por medio de los cuales se acrecientan los recursos y condiciones de resguardo social. Las inteligencias sociales instauran y difunden significaciones ligadas a circunstancias comunes al tiempo que despliegan y conceden vínculos de poder. El poder social se define en la imposición de voluntades y dominios (Weber, 2010). Las relaciones humanas evidencian

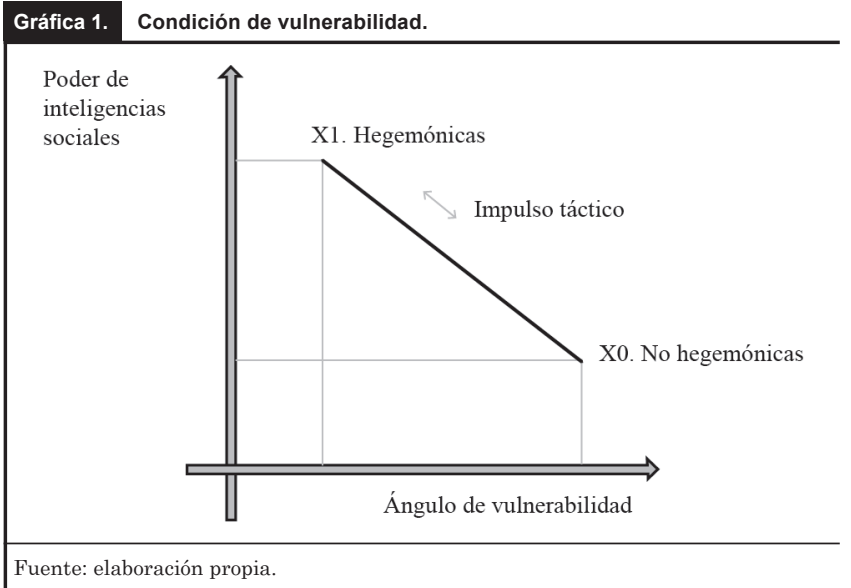

3. En el 2011 Howard Gardner recibió el Premio Príncipe de Asturias de Ciencias Sociales por sus notables contribuciones a las ciencias sociales. (1974) y Paul Hirts (1979) que Howard Gardner reformula la visión de inteligencia humana reivindicando la existencia de tantas inteligencias como maneras de resolver problemas, obtener aprendizajes y propiciar desarrollos personales. las asimetrías sectoriales que derivan del dominio de aquellas inteligencias sociales capaces de anticipar y resolver, de mejor manera, las situaciones presentes subordinando los demás segmentos. El avance de cada inteligencia social implica de este modo la historia particular de luchas y alianzas llevada a cabo en su favor. Al respecto, es importante advertir la manera de cómo el juego de poder entre los grupos configura un escenario de transición que involucra reacciones, imposiciones y declinaciones (Foucault, 1980). En tal lucha el exterminio de las inteligencias opositoras resulta innecesario dado que apremia imponer los esquemas que permitan a cada inteligencia extender sus asuntos, aún rivalizando con otras lógicas imperantes.

\section{La teoría de las inteligencias sociales}

La teoría de las inteligencias sociales afirma que la vida de los colectivos favorece la aproximación de las capacidades intelectivas de los individuos y grupos al encontrase presionadas por el entorno global. Las personas proceden a organizarse y actuar sobre la base de las inteligencias más fortalecidas, dado que reportan mayores beneficios materiales o anímicos a quienes participan de ellas. La teoría también considera a los argumentos capaces de soportar los discursos y visiones disímiles del mundo global que alimentan los procesos y las estructuras simbólicas que despliegan los diversos modos de vida (Geertz, 2006).

Un ser humano al encontrarse desprovisto de contacto y respaldo social resulta vulnerable. Por este motivo cada individuo es conducido a identificarse y relacionarse con agrupamientos cuya trayectoria pueda aminorar su sensación de desamparo, sea ésta real o imaginaria. A esta circunstancia por su variabilidad la denominaremos ángulo de vulnerabilidad. Todas las sociedades al expandir y diversificar sus relaciones interpersonales multiplican las formas de inteligencia social, al propiciar rivalidad y hegemonía entre las diversas versiones da lugar una lucha efectiva o latente en el plano racionalsimbólico que modifica el ángulo de vulnerabilidad de los individuos y grupos. Con el propósito de incrementar su poder sobre el conjunto, todos los individuos tienden a situarse, en la medida de sus posibilidades y capacidades, en la trama de inteligencias sociales existente y así aprovechar aquellas que les ofrezcan mayores ventajas y perspectivas. A la posibilidad de transitar de una inteligencia a otra y beneficiarse con tal acción le denominaremos impulso táctico (gráfica 1).

Las inteligencias sociales describen el fenómeno psicológico por medio del cual se forman, reproducen y renuevan las alianzas sociales. Cada contexto y situación por tanto favorece o no la presencia y predominio de inteligencias. 
En condiciones de globalidad las inteligencias sociales que adquieren posición hegemónica y favorecen sus procesos de reclutamiento demográfico son las de tipo: a) empresarial, b) científica, $c$ ) estatista y $d$ ) delictiva. Cada una de ellas susceptible de operar de manera independiente o conjunta.

El escenario global no quedaría completo sin tomar en cuenta la presencia de las inteligencias sociales provenientes del pasado y que continúan desempeñando un papel importante para algunos colectivos nos referimos a la inteligencia ingenua, matriz de todas las inteligencias y las metafísicoreligiosas, contraculturales, lúdico-deportivas y estetizantes.

\section{1. Las inteligencias sociales hegemónicas}

El contexto global de las sociedades no puede apreciarse sin tomar en cuenta los crecientes flujos económicos e informativos que impactan a los individuos en sus diversos modos de inteligencia y que resignifican sus expectativas de vida y perspectivas de la realidad local. Al respecto, a continuación de presentan las inteligencias sociales que hoy se muestran más estructuradas:

a) Inteligencia empresarial: propia de la mentalidad capitalista y que se especializa en resolver asuntos vinculados al mundo de los negocios, el bienestar material y las expectativas consuntivas. Se vincula con las actividades generadoras de riqueza ocupándose de elevar las utilidades, incrementar el patrimonio e incidir sobre los mercados. Bajo la lógica empresarial y de capitalización, los asuntos laborales se subordinan a los objetivos de rentabilidad al grado de mercantilizar las relaciones interpersonales y manipular los imaginarios implicados.

b) Inteligencia científica: opera con base en los conocimientos teóricos, académicos y científicos disponibles. Es resultado de los modelos explicativos y comprensivos difundidos sobre el medio social y que dan cuenta del mundo real. Su lógica argumentativa se encuentra soportada en los criterios de objetividad, exactitud, veracidad y verificabilidad. Al respecto, las nociones de habitus y campo científico ayudan a esclarecer el comportamiento de las sociedades científicas (Bourdieu, 2001), más cuando se consideran los protocolos de mérito y criterios de textualidad propios de las actividades teoréticas.

c) Inteligencia estatista: ${ }^{5}$ esta perspectiva anticipa, cuestiona y valida las estructuras de autoridad y gobierno al seno de cada sociedad. Su lógica propicia acomodos y consensos políticos entre las masas y las dirigencias. Las formulas estatistas incluyen versiones autoritarias, democráticas, partidistas, legalistas y hasta acciones subversivas que presuponen alguna ideología, un sistema de valores y suficientes cauces de participación social. La inteligencia estatista articula las voluntades colectivas con los principios de gobernabilidad que emergen del orden social y para tal efecto instaura el régimen de derechos conferidos que sustenta el modelo de justicia prevaleciente. Esta inteligencia es responsable de erigir y mantener la institucionalidad y el sentido de pertenencia e identidad gregaria entre los individuos.

d) Inteligencia delictiva: constituye una inteligencia trasgresora la cual, por medio del engaño y la fuerza, violenta y trastoca los derechos civiles instituidos. La inteligencia delictiva es promotora de actos ilícitos de diversa magnitud que causan daño a las víctimas y generan inseguridad en la población. Sus acciones siembran inseguridad, intimidan y provocan psicosis colectiva. Las inteligencias delictivas suelen apropiarse de los espacios y asuntos poco definidos por otras inteligencias y con ello obtienen suficientes beneficios económicos y simbólicos. La inteligencia delictiva instaura un ambiente criminal que desafía las fuerzas estatistas. La inteligencia delictiva trastoca las relaciones humanas promoviendo la ambición desmedida y la violación de normas como recurso válido.

Las inteligencias sociales hegemónicas no permanecen aisladas, ${ }^{6}$ ni confinadas a los principios que les originaron, por el contrario se aproximan, fusionan y tienden a ser partícipes de luchas orientadas a incrementar su influencia y poderío en el escenario global (figura 1). La composición y estatus que adquieren las inteligencias sociales resulta distinta en cada región del planeta. En algunos casos la inteligencia científica aparecerá articulada a la inteligencia

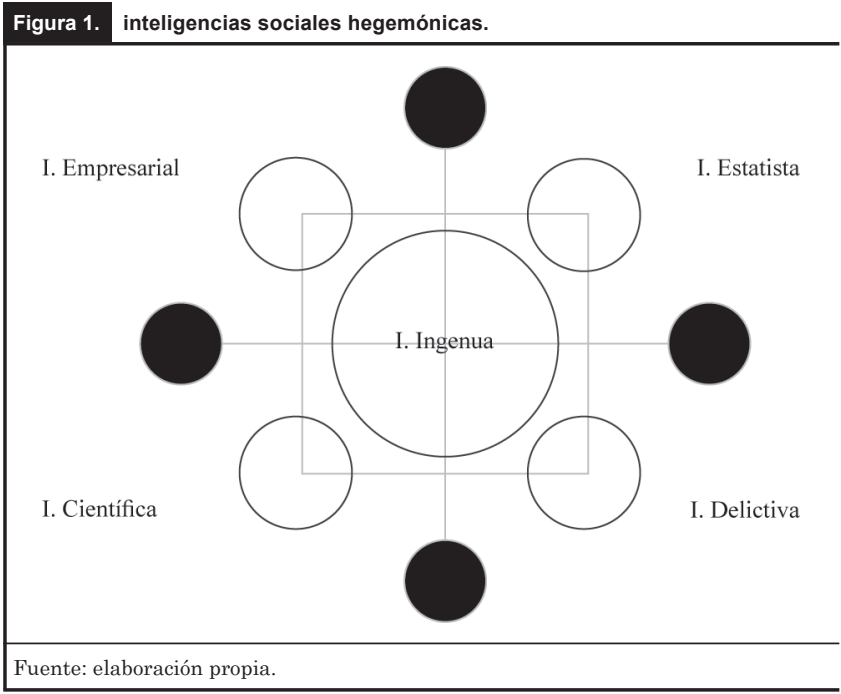

5. Optamos por emplear el término estatista y no el de política, dado que todas las inteligencias sociales mantienen una acción política.

6. Una inteligencia social centrada en sí misma propicia su cuestionamiento. Ejemplo de ello son las sociedades altamente tecnificadas que confiadas en el poder de su ciencia originan perjuicios a la población 
empresarial logrando impulsar los sectores productivos. La justa colaboración entre las inteligencias empresariales y estatistas da confianza a los inversionistas y brinda seguridad a los trabajadores. La relación entre inteligencias científicas y estatistas propicia gobiernos tecnocráticos, eficientes e insensibles a las demandas sociales. La inteligencia delictiva vinculada con la inteligencia empresarial hace prosperar los esquemas de capitalización de negocios ilícitos encubiertos de cierta legalidad. Al relacionarse la inteligencia delictiva con la inteligencia estatista se propician prácticas corruptas. La complicidad de servidores públicos con núcleos o células delictivas favorece la descomposición social y el descrédito de las instituciones. La extraña combinación entre inteligencias científicas y delictivas fortalece los modos de operar del crimen organizado brindando recursos tácticos a sus células.

\section{2. Inteligencias sociales no hegemónicas}

El escenario se complementa con la presencia de las inteligencias no hegemónicas que juegan un papel decisivo a nivel local (figura 2). Entre ellas destaca la inteligencia ingenua que constituye una forma de racionalidad primigenia ocupada de los asuntos ordinarios. Aparece como una inteligencia libre, generosa y carente de finalidades preestablecidas. Tal inteligencia sustenta las relaciones interpersonales, favorece el contacto humano y cede espacio a otras inteligencias sociales. ${ }^{7}$ Del conjunto de inteligencias sociales que la era global ha situado en condiciones no hegemónicas destacan las siguientes:

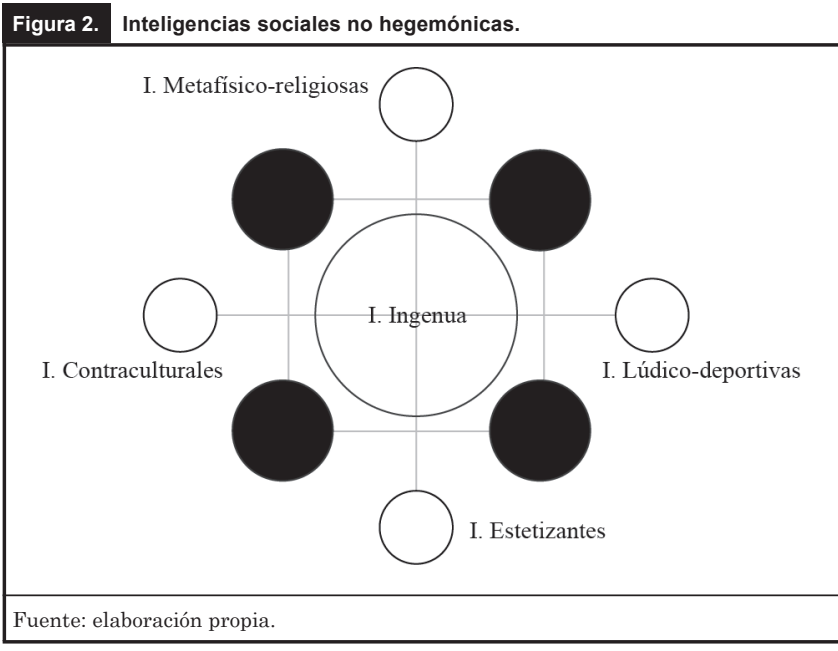

7. En la actualidad el margen de acción propio de la inteligencia ingenua depende de la posición conferida a otras inteligencias sociales. Apropiarse de los recovecos de la inteligencia ingenua y desplazar otras inteligencias representa el primer objetivo de las inteligencias sociales hegemónicas. a) Inteligencias metafísico-religiosas: fundamentan sus planteamientos y acciones en creencias colectivas que trascienden los referentes físicos y naturales. Estas inteligencias sociales instauran y mantienen sentidos de vida comunitarios con base en dogmas, rituales y principios morales que sustentan experiencias espirituales e hierofanías personales.

b) Inteligencias contraculturales: se vinculan con movimientos sociales impulsados por minorías rebeldes, cuyas propuestas se confrontan de manera intencional con los modelos culturales dominantes. Se trata de esquemas alternos con cierta persistencia en el tiempo, los cuales ofrecen a sus seguidores alternativas de liberación pero sin capacidad de generalizarse y traducirse en un orden sustitutivo.

c) Inteligencias lúdico-deportivas: son aquellas versiones que legitiman el juego, la habilidad física y la diversión entre individuos y grupos. Sus manifestaciones alientan las destrezas requeridas en situaciones de ocio, azar y competencia. Su finalidad radica en encausar el afán de lucha y victoria entre dos o más bandos sin provocar violencia extrema. Los eventos promovidos por sus inteligencias expresan el interés de los practicantes y observantes por lograr el mayor nivel de convocatoria social posible.

d) Inteligencias estetizantes: son responsables del desarrollo sensible hedonista y suprasimbólico de la sociedad. Su intervención modifica el gusto personal al proponer las manifestaciones y objetos que despiertan inquietudes culturales y son asimilables. Su impulso contribuye a movilizar las capacidades sensitivas y subjetivas de la colectividad.

En condiciones de libre mercado las inteligencias sociales no hegemónicas se articulan a las inteligencias dominantes por medio de alianzas que les fortalecen. Ejemplo de ello es la combinación entre inteligencias empresariales, estetizantes y lúdico-deportivas, cuya mezcla garantiza lucrativos beneficios a los inversionistas. En varias regiones del planeta las inteligencias estatistas y religiosas han conseguido mancomunar sus proyectos logrando obtener el control ideológico y la obediencia de sus seguidores, lo cual les evita recurrir a formas más represivas.

La inteligencia delictiva influye también sobre las inteligencias no hegemónicas, en particular en las sociedades donde la conciencia ciudadana no se encuentra suficientemente fortalecida. Como ya se mencionó el crimen tiende a corromper la vida institucional trastocando sus finalidades y sentidos.

Respecto a los medios de comunicación, nos resistimos a considerarlos una inteligencia social en sí misma debido a que constituyen agregados de tecnologías y dispositivos por medio de las cuales las inteligencias sociales hegemónicas y no hegemónicas acrecientan su presencia en la sociedad. 


\section{Dos panoramas de globalidad en el mundo}

Cada país incursiona en la globalización experimentando una composición particular de sus inteligencias sociales. A continuación se expone de manera sucinta lo que, desde la teoría propuesta, acontece en México y España.

\section{1. Caso mexicano}

El Tratado de Libre Comercio (TLC) con EE. UU. y Canadá introdujo a México de forma precipitada en una economía mercantil de corte liberal. Como consecuencia, el desarrollo regional se subordinó al comportamiento de la economía norteamericana. La inteligencia empresarial en México adoptó los modelos administrativos exigidos por los socios comerciales. El intercambio mercantil desigual produjo la extinción de las empresas menos competitivas, hecho que incrementó el desempleo y la emigración. Actualmente la inteligencia empresarial nacional se muestra más exigente y crítica en torno a las acciones emprendidas por el sector público pero carente de asumir un compromiso social relevante.

La inteligencia científica ha venido prosperando en el país un tanto desvinculada de la dinámica económica y social. En general, continúa siendo dependiente de los recursos públicos que resultan insuficientes para apuntalar desarrollos relevantes. Al encontrarse limitadas las capacidades científicas los investigadores y tecnólogos no participan en grandes proyectos, menos aún en la toma de decisiones importantes. La ciencia requerida por las grandes empresas continúa siendo transferida desde los países desarrollados (figura 3).

La inteligencia estatista, a pesar de los avances democráticos y la alternancia en todos los niveles de gobierno, se observa debilitada frente a la opinión ciudadana al ser demagógica y no pocas veces corrupta. Su injerencia intermitente en asuntos del bienestar social alienta el reclamo generalizado en contra de los partidos políticos, las instituciones públicas y los actores políticos quienes continúan siendo ejemplo de improvisación, ineficiencia, abuso e impunidad.

La inteligencia delictiva en México ha logrado penetrar en las instituciones de Estado como en las empresas privadas. Desde las prácticas toleradas de corrupción en la vía pública, hasta los actos de extrema violencia consumados por el crimen organizado, los actos delictivos están presentes en buena parte del territorio nacional y hacen presa fácil a aquellos grupos sociales en abandono y desencanto.

En cuanto a las inteligencias no hegemónicas que aún mantienen presencia social, los discursos metafísico-religiosos tienden a diversificarse y muestran mayor tolerancia hacia nuevos cultos. Las inteligencias lúdico-deportivas, siendo muy atrayentes, son artificiosamente exaltadas por la visión mediática y mercantilista que desvirtúa sus finalidades e impide el desarrollo sistémico de sus prácticas. Las inteligencias contraculturales prosperan más entre los sectores populares debido a sus expectativas y baja capacidad ofensiva. Las inteligencias estetizantes son asumidas de forma acrítica y fragmentada en la población; sin embargo, prosperan cuando liberan a la sociedad de viejos prejuicios.

\section{2. Caso español}

La Unión Europea significa, en el contexto de la globalización, el esfuerzo más notable por integrar una región multicultural en una misma perspectiva económica y política. A pesar de las dificultades que supone la presencia de diversas lenguas y tradiciones para la construcción de una ciudadanía europea, el esfuerzo comunitario, aún después del Brexit, se mantiene vigente y el espíritu solidario se manifiesta en asuntos y espacios comunes.

La inserción de España en la Unión Europea ha tenido un papel decisivo en la transformación de la nación abatiendo las secuelas de la vieja dictadura. El propósito de conformar una sociedad libre y democrática con economía moderna y abierta al mundo le ha permitido a España disponer de mejor calidad de vida y mayores flujos de inversión

En la actualidad su inteligencia empresarial utiliza esquemas administrativos avanzados que confieren suficiente movilidad a los corporativos y resignifican la identidad regional española. El reto de dicha inteligencia empresarial radica en alinear las estructuras productivas con las prioridades de la Unión Europea ampliando las fuentes de empleo y la movilidad de los sectores juveniles.

La inteligencia científica, a pesar de las fortalezas académicas, se encuentra en proceso de coexistir con la realidad económica y social de la nación. Este objetivo supondría sustituir el paradigma ilustrado por un pensamiento orien-

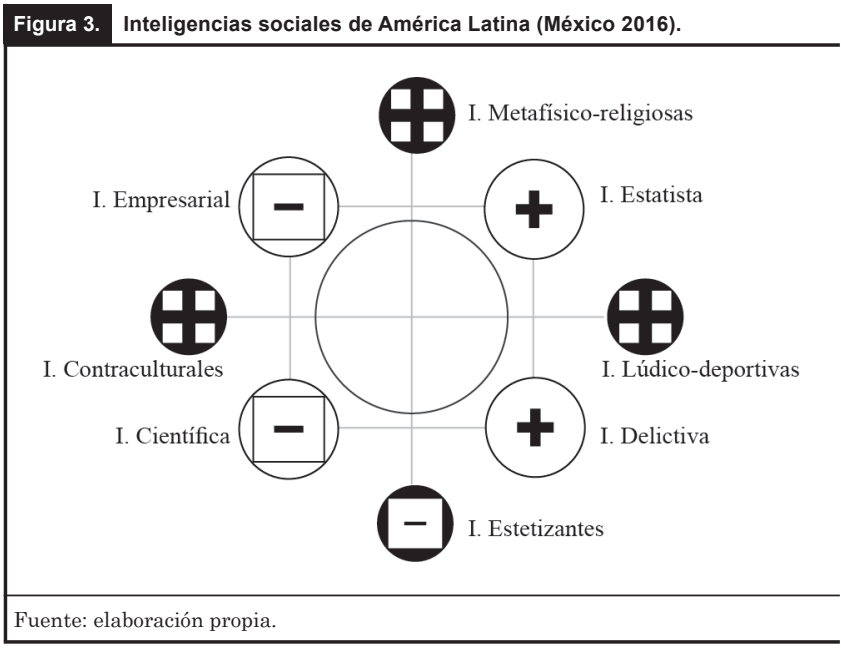


tado a generar mayor productividad y participar de manera deliberada en la toma de decisiones (figura 4).

La inteligencia estatista se encuentra influida con fuerza por la Unión Europea y, aunque dividida, se ha enriquecido por la alternancia política de los gobiernos de derecha e izquierda. Sus condiciones institucionales favorecen las prácticas democráticas dando por resultado una sociedad suficientemente crítica y participativa. La inteligencia delictiva, a pesar del desempleo y la corrupción, hasta el momento no ha logrado prosperar, ni afectar de modo sensible a los sectores sociales. El índice de percepción del crimen ha disminuido en los últimos años gracias a las acciones y dispositivos de visibilidad social. En el mismo sentido, los actos terroristas se han disipado dando paso a formas alternas de reclamo.

Las inteligencias no hegemónicas continúan latentes pero cada vez más cercanas al ámbito privado. Los discursos metafísico-religiosos han resultado poco atrayentes a la población juvenil. Por el contrario, las inteligencias contraculturales han venido incrementado su influencia y capacidad ofensiva en

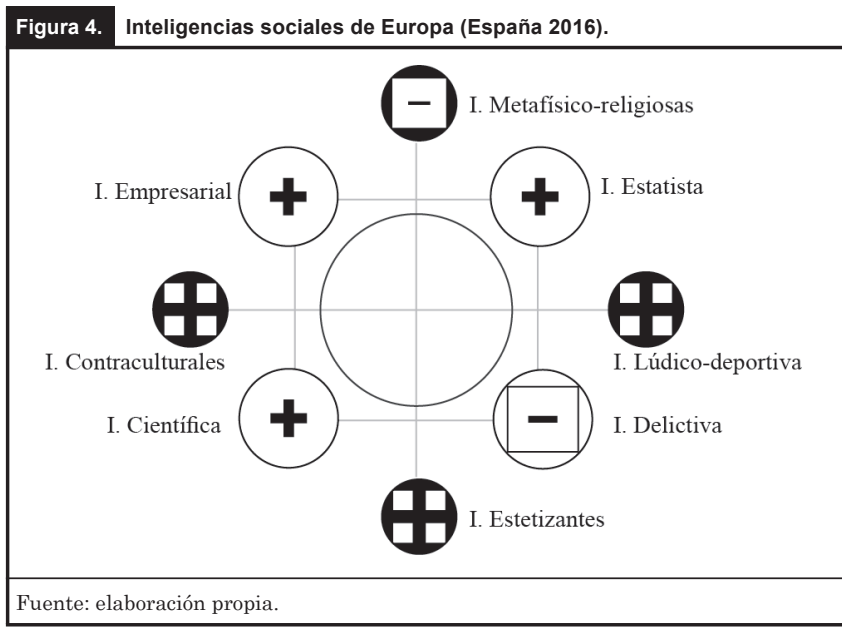

la sociedad. Las inteligencias lúdicas y deportivas muestran un desarrollo notable al favorecer la integración social. Las inteligencias estetizantes se mantienen activas mostrando suficiente capacidad de propuesta.

\section{Discusión y prospectiva}

La teoría de las inteligencias sociales, cuyos esbozos hemos expuesto, deriva del primer ejercicio de hermenéutica analógica orientada a la comprensión de los fenómenos sociales que derivan de la globalidad. Su importancia radica en propiciar una vía alterna de interpretación orientada a esclarecer las diversas lógicas que operan en la sociedad actual tomando en cuenta las instancias que adquieren posición hegemónica en el conjunto.

El modelo confirma que las inteligencias sociales son responsables de configurar un escenario de elección entre los individuos y grupos que producen y reproducen posturas vinculadas con los asuntos y dominios que impactan el devenir de las colectividades al instaurar propósitos, cursos y sentidos de vida.

Como escenario tentativo para las próximas décadas, se avizora que el avance del capitalismo habrá de afianzar la supremacía del mercado sobre el resto de las dinámicas sociales. Este asunto contribuirá al fortalecimiento de las inteligencias empresariales, como también de las inteligencias delictivas, incluso en contextos desarrollados. La inteligencia científica continuará mostrándose dependiente de las directrices empresariales y habrá de concentrar sus esfuerzos en la diversificación de satisfactores y medos que contribuyan a sanear los modos de vida. La inteligencias estatistas, en la medida que no obtengan consensos importantes, harán ilegítimas sus políticas, caerán en descrédito y con ello favorecerán la emergencia de movimientos civiles y conformación de comunidades autónomas que podrían originar la presencia de nuevas inteligencias globales.

Referencias

Bourdieu, P. (2001). El oficio del científico. España: Anagrama.

Beuchot, M. (2004). Hermenéutica, analogía y símbolo. México: Herder

Beuchot, M. (2005). Tratado de bermenéutica analógica. Hacia un nuevo modelo de interpretación. México: Itaca-UnAm.

De Sousa, B. (2015). Una epistemología del sur. México: Siglo XXI-CLACSO.

Ferraris, M. (1998). L'ermenentica. Roma: Editori Laretza.

Foucault, M. (1980). Microfísica del poder. España: Ediciones La Piqueta.
Gadamer, H. G. (2010). Verdady método. España: Ediciones Sígueme.

Gadamer, H. G. (1984). Una lingua contro il fanatismo. Conferencia en Universidad de Roma, La Sapienza. Italia.

García, J. (2001). Metafísica tomista. Ontología, gnoseologia y teología natural. España: Eunsa.

Gardner, H. (2001). Estructuras de la mente: la teoría de las inteligencias múltiples. México: Fondo de Cultura Económica.

Geertz, C. (2006). La interpretación de las culturas. España: Gedisa.

Gross, L. (1974). Modes of communication and the acquisition of symbolic capacities. Chicago.

Guilford, J. P. (1967). The nature \& buman Intelligence. New York: McGraw-Hill.

Hirts, P. (1979). Knowledge and the curriculum. London: Routledge \& K. Paul.

Thurstone, L. L. (1960). The nature of intelligence. Paterson: Littlefield, Adams \& Co.

Touraine, A. (2014). Crítica de la modernidad. México: Fondo de Cultura Económica.

Weber, M. (2010). Conceptos sociológicos fundamentales. España: Alianza Editorial.

Velázquez, M. (2011). Seminario de Hermenéutica. México: Universidad Autónoma del Estado de México. 